\title{
GÊNERO NA FORMAÇÃO EM PEDAGOGIA: CONCEPÇÕES DE FUTURAS(OS) DOCENTES A PARTIR DE CINCO CONCEITOS
}

\author{
MATHEUS ESTEVÃO FERREIRA DA SILVA ${ }^{1}$ \\ ORCID: https://orcid.org/0000-0002-2059-6361 \\ TÂNIA SUELY ANTONELLI MARCELINO BRABO ${ }^{2}$ \\ ORCID: https://orcid.org/0000-0002-9833-0635
}

ALESSANDRA DE MORAIS ${ }^{3}$

ORCID: https://orcid.org/0000-0001-5521-9307

\begin{abstract}
RESUMO: Este artigo objetivou apresentar as concepções de graduandas(os) em Pedagogia, de uma universidade pública paulista, sobre o conceito de gênero, relacionando os conceitos evidenciados em suas concepções com a produção da literatura de gênero feminista. Para tal, explora-se resultados obtidos a partir de um questionário aberto, utilizando-se da técnica de Análise de Conteúdo (AC). A amostra participante consistiu em 165 sujeitos $(\mathrm{N}=165)$, matriculados nos anos inicial e final do curso, que ambientou a pesquisa, o que atribuiu à investigação o desenho transversal de pesquisa. Ressalta-se que as concepções das(os) graduandas(os) sobre o conceito de gênero distribuíram-se em cinco principais conceitos: em concepção 1) polissêmica; 2) biologizante e religiosa; 3) funcionalista; 4) identitária; e 5) associada à sexualidade. Conclui-se que as(os) participantes não detêm uma formação em gênero fundada no conhecimento científico proveniente das produções da literatura de gênero feminista, com exceção das(os) que compreendem gênero nas perspectivas identitária e funcionalista, mas que se mostram em noções frágeis e sem a evocação de determinada teoria ou autor(a) da literatura.
\end{abstract}

Palavras-chave: Educação; Gênero; Formação inicial docente; Pedagogia.

\section{GENDER IN THE PEDAGOGY FORMATION: CONCEPTIONS OF FUTURE TEACHERS AS OF FIVE CONCEPTS}

\begin{abstract}
This article aimed to present the conceptions of undergraduate students in Pedagogy, from a public university in São Paulo, about the concept of gender, relating the concepts evidenced in their conceptions with the production of feminist gender literature. For such, it explores results obtained from an open questionnaire, using the technique of Content Analysis (CA). The participant sample consisted of 165 subjects $(\mathrm{N}=165)$, enrolled in the initial and final years of the course, which set the research, which attributed to the investigation the cross-sectional research design. It is noteworthy that the conceptions

\footnotetext{
${ }^{1}$ Universidade Estadual Paulista “Júlio de Mesquita Filho” (UNESP). Marília, SP, Brasil. <matheus.estevao2@hotmail.com>

2 Universidade Estadual Paulista "Júlio de Mesquita Filho" (UNESP). Marília, SP, Brasil. <tamb@terra.com.br>

3 Universidade Estadual Paulista "Júlio de Mesquita Filho" (UNESP). Marília, SP, Brasil. <alemorais.shimizu@gmail.com> 
of the undergraduate students about the concept of gender were distributed in five main concepts: in conception 1) polysemic; 2) biologizing and religious; 3) functionalist; 4) identity; and 5) associated with sexuality. It is concluded that the participants do not have a formation in gender based on the scientific knowledge coming from the productions of the feminist gender literature, with the exception of those who understand gender in the identitarian and functionalist perspectives, but that show themselves in fragile notions and without the evocation of a certain theory or author of the literature.

Keywords: Education; Gender; Initial teacher formation; Pedagogy.

\section{GÉNERO EN LA FORMACIÓN EN PEDAGOGÍA: CONCEPCIONES DE FUTUROS DOCENTES BASADAS EN CINCO CONCEPTOS}

RESÚMEN: Este artículo tuvo como objetivo presentar las concepciones de estudiantes de pregrado en Pedagogía, de una universidad pública de São Paulo, sobre el concepto de género, relacionando los conceptos evidenciados en sus concepciones con la producción de literatura de género feminista. Para este propósito, se exploran los resultados obtenidos de un cuestionario abierto, utilizando la técnica de Análisis de Contenido (AC). La muestra participante consistió en 165 sujetos (N=165) matriculados en los años iniciales y finales del curso que establecieron la investigación, lo que atribuyó el diseño transversal de la investigación a la investigación. Cabe señalar que las concepciones de los estudiantes de pregrado sobre el concepto de género se dividieron en cinco conceptos principales: en la concepción 1) polisémica; 2) biologizante y religioso; 3) funcionalista; 4) identidad; y 5) asociado con la sexualidad. Se concluye que las participantes no tienen una capacitación en género basada en el conocimiento científico de las producciones feministas de literatura de género, con la excepción de aquellas que entienden el género en las perspectivas identitarias y funcionalistas, pero que se muestran en nociones frágiles y sin evocar una teoría particular o autor de la literatura.

Palabras clave: Educación; Género; Formación inicial del profesorado; Pedagogía. 


\section{INTRODUÇÃO: DA PESQUISA À PRESENTE PRODUÇÃO}

Este artigo é resultado de uma pesquisa concluída, desenvolvida entre os anos de 2017 e 2018, que contou com o financiamento da Fundação de Amparo à Pesquisa do Estado de São Paulo $(\text { FAPESP })^{4}$. Nessa pesquisa, em síntese, objetivou-se investigar a formação de graduandas(os) em Pedagogia sobre as temáticas de gênero e sexualidades e suas atitudes diante da diversidade sexual e de gênero na escola. Ao mesmo tempo, a pesquisa também objetivou relacionar essa formação sobre as temáticas do grupo participante da pesquisa com a sua formação ética, do ponto de vista do desenvolvimento moral, nas abordagens kohlberguiana e neo-kohlberguiana (Lawrence KOHLBERG, 1992; Moshe M. BLATT; KOHLBERG, 1975; James REST et al., 1999).

De caráter interdisciplinar e vinculando-se aos campos de estudos e conhecimentos: 1) Educação em direitos humanos, 2) Estudos de Gênero e 3) Psicologia do Desenvolvimento Moral, a pesquisa teve seu desenvolvimento culminado em meio a um caloroso debate travado em âmbito nacional para a retirada dos termos gênero e orientação sexual dos Planos Municipais, Estaduais e Nacional de Educação, debate posto entre os anos de 2014 e 2015, no momento da elaboração de políticas públicas. $\mathrm{Na}$ época, não apenas pesquisas recentes apontavam dificuldades para a efetivação da educação em direitos humanos junto a temas relativos à diversidade humana nas instituições de ensino, mas também, a conjuntura política apontava a resistência em relação a esses temas por parte dos(as) responsáveis pela elaboração das políticas públicas para o sistema educacional brasileiro, conforme pontuamos em trabalho anterior (Matheus Estevão Ferreira da SILVA; Tânia Suely Antonelli Marcelino BRABO; Alessandra de MORAIS, 2017).

$\mathrm{Na}$ pesquisa, as temáticas de gênero e sexualidades foram abordadas como um problema da educação em direitos humanos (EDH), proposta educacional deferida legalmente no país desde 2006 (BRASIL, 2007; 2012; 2013). Voltada para a transformação social e formação de sujeitos de direitos, com previsão de desenvolvimento em todos os níveis de ensino, a proposta da EDH é orientada de modo a contemplar outras temáticas - para além da temática homônima que carrega -, tais como gênero e sexualidades, porém que devem ser desenvolvidas juntas aos e na perspectiva dos direitos humanos.

Em sua redação, o Plano Nacional de Educação em Direitos Humanos (PNEDH), um dos documentos basilares da educação em direitos humanos no país, define, como um de seus objetivos, a superação de desigualdades afirmadas na história nacional, muitas delas caracterizadas pela "[...] intolerância étnico-racial, religiosa, cultural, geracional, territorial, físico-individual, de gênero, de orientação sexual, de nacionalidade, de opção política, dentre outras” (BRASIL, 2013, p. 21).

Assim, no trabalho com a educação em direitos humanos, abordar gênero e sexualidades é tratar dos direitos dos sujeitos que protagonizam ambas as temáticas: mulheres e LGBTs ${ }^{5}$, além de diversas outras questões que permeiam as temáticas. Teve-se como uma das hipóteses, confirmadas em investigação empírica, que, quando a $\mathrm{EDH}$ é acompanhada pelos referidos dois temas relativos à diversidade, ela tem ainda menos chances de ser efetivada, visto que sua abordagem nas instituições de ensino depende dos conhecimentos e das disposições que professoras(es) mantêm, entre as(os) principais profissionais responsáveis por essa abordagem, para com os temas e seus protagonistas.

Quando examinamos, especificamente, a formação em Pedagogia, nos deparamos com experiências como a de Roney Polato de Castro (2016, p. 208, grifos nossos), em que traz o seguinte relato de uma das entrevistadas de sua pesquisa de Doutorado sobre o posicionamento de professoras

\footnotetext{
${ }^{4}$ A pesquisa teve como título Educação em direitos bumanos, gênero e sexualidades, e desenvolvimento moral na formação docente: conhecimentos, concepsões e condutas de graduandos(as) em Pedagogia de uma universidade pública do estado de São Paulo, financiada pela FAPESP pelo processo de n. ${ }^{\circ}$ 2017/01381-9 e com vigência de 01/05/2017 a 31/12/2018 na linha de fomento de Programas Regulares de Bolsas no País em Fluxo Contínuo, e realizada sob orientação das Prof. ${ }^{a}$ Dr. ${ }^{a}$ Tânia Suely Antonelli Marcelino Brabo e Prof. ${ }^{a}$ Dr. $^{a}$ Alessandra de Morais. Disponível em: https://bv.fapesp.br/pt/bolsas/170898/educacao-em-direitoshumanos-genero-e-sexualidades-e-desenvolvimento-moral-na-formacao-docente-co/

${ }^{5}$ Neste artigo usaremos da sigla LGBT para referenciar a diversidade sexual e de gênero LGBTQIA+, que inclui lésbicas, gays, bissexuais, transexuais, travestis, transgêneros, queers, intersexuais, assexuais e etc. Historicamente nos Estudos de Gênero, foram as mulheres que primeiro protagonizaram as teorizações do campo e, somente depois, incluiu-se a população LGBT.
} 
perante a expressão da identidade de gênero (que elas associaram à sexualidade) de um dos alunos da escola que ambientou a referida pesquisa:

Estava em uma escola de educação infantil e indo para a sala dos professores me deparei com a seguinte cena: um grupo de professoras fazendo comentários depreciativos em relação a um aluno que elas diziam ser 'viadinho'. As 'docentes' [...] falavam, entre gargalhadas, que o menino ficava igual a uma bichinha na fila de entrada e que quando crescesse não escaparia de ser gay. Fiquei até com vergonha de ouvir as palavras delas em relação ao aluno.

Ressalta-se que, se a professora nutre tal conhecimento e disposição ${ }^{6}$ para com seu aluno, não haverá como ela trabalhar a educação em direitos humanos de modo efetivo, muito menos em gênero e sexualidades. Logo, a relevância do trabalho da(o) profissional em Pedagogia é colocada pela escola de Educação Infantil e Ensino Fundamental I - níveis de ensino encarregados à(ao) pedagoga(o) -, ser o primeiro "[...] agente de socialização coletivo para com a diversidade fora do seio familiar, em que a educação em direitos humanos tem início. Se desde lá essa educação é prejudicada ou desvirtuada, os preceitos previstos por essa educação, definitivamente, não se consolidarão" (SILVA; BRABO; MORAIS, 2017, p. 1279).

Durante a etapa empírica da pesquisa, entre os instrumentos que utilizamos para coleta de dados no cumprimento dos critérios e objetivos traçados, esses se trataram, respectivamente, de grupos focais, técnica qualitativa de pesquisa; de um questionário, instrumento quantitativo, que foi elaborado de forma a compor perguntas abertas e dilemas morais na proposta kohlberguiana (BLATT; KOHLBERG, 1975); e do Defining Issues Test 2 (DIT-2), instrumento quantitativo fechado e validado de medida do juízo moral.

Então, compreendida a proposta da pesquisa, para a produção deste artigo, decidimos apresentar resultados parciais obtidos com a aplicação do questionário, assim como traçarmos algumas considerações sobre o processo de elaboração desse instrumento. A aplicação do questionário se ateve, especificamente, ao cumprimento da primeira parte do objetivo da pesquisa, ou seja, o de investigar a formação dos sujeitos participantes - graduandas(os) em Pedagogia - em gênero e sexualidades, de modo a compreender o estado dessa formação, se satisfatória ou não com base na literatura e documentos oficiais pertinentes.

As perguntas abertas foram inseridas no questionário para extração das concepções (e, por conseguinte, dos conhecimentos que constituem essas concepções) que os sujeitos dispõem sobre as temáticas, enquanto os dilemas morais foram inseridos para coleta das possíveis condutas dos mesmos sujeitos diante do público em questão. Devido à impossibilidade de produzir uma discussão que abrangesse todos os resultados alcançados com o instrumento, foi necessário atribuir algum tipo de recorte para este texto e, por isso, decidimos abordar os resultados obtidos em somente uma das perguntas abertas do questionário, a qual interrogava sobre o conceito de gênero.

Dessa forma, delimitada a abrangência deste artigo na exposição dos resultados alcançados a partir das análises feitas nos numerosos dados coletados pelos, também numerosos, instrumentos utilizados na pesquisa, este texto tem como objetivo apresentar as concepções de graduandas(os) em Pedagogia, de uma universidade pública paulista, sobre o conceito de gênero, relacionando os conceitos evidenciados em suas concepções com a produção da literatura de gênero feminista consultada.

Com base na revisão de literatura que realizamos nas bases de dados Portal de Periódicos da CAPES (Coordenação de Aperfeiçoamento de Pessoal de Nível Superior) e SciELO (Scientific Electronic Library Online), durante a consulta e fundamentação na referida literatura, encontramos alguns poucos trabalhos (artigos) pertinentes e com propostas similares à presente produção que merecem ser aqui citados. Utilizando-se dos descritores gênero e Pedagogia e delimitando a busca para trabalhos na língua portuguesa, no Portal de Periódicos da CAPES encontramos 18 trabalhos que compartilham esses

\footnotetext{
${ }^{6}$ Tal como em trabalho anterior, por disposições compreende-se aqui como as "[...] posições valorativas que um sujeito dispõe sobre um determinado objeto, que pode ser uma ideia, um conceito, comportamento, etc., posições que geram predisposições particulares em relação a esse objeto e que podem ser positivas ou negativas a ele" (Matheus Estevão Ferreira da SILVA, 2020, p. 71).
} 
descritores no título, sendo que apenas 02 deles (Nilson Fernandes DINIS; Roberta Ferreira CAVALCANTE, 2008; Ana Paula COSTA; Paulo Rennes Marçal RIBEIRO, 2011) compartilham da proposta de investigar a formação de graduandas(os) ou graduadas(os) em Pedagogia sobre o conceito de gênero. Com os mesmos descritores, no SciELO encontramos um total de 05 trabalhos, sendo também 02 específicos à proposta em comum, os mesmos encontrados na busca anterior.

Em seu texto, Dinis e Cavalcante (2008) discutem concepções de graduandas(os) em Pedagogia da Universidade Federal do Paraná (UFPR) sobre os temas homossexualidade e, aqui o nosso foco, gênero. De forma diferente dos autores, optamos por não divulgar o nome da universidade que tivera seu curso de Pedagogia investigado por nossa pesquisa, por questões éticas, bastando saber que essa se trata de uma universidade pública localizada no estado de São Paulo que, quanto ao seu curso de Pedagogia, com quatro anos de duração, admite (ingressantes) e forma (concluintes) cerca de 120 estudantes por ano.

Já no texto de Costa e Ribeiro (2011), as autoras pesquisaram as concepções sobre relações de gênero de um grupo de alunas do curso de Pedagogia da Universidade Estadual Paulista (UNESP), campus de Araraquara, que já atuavam, porém, na educação escolar como professoras. Também de forma diferente das autoras, além da não divulgação da universidade que ambientou a pesquisa, sua investigação teve como objeto a formação docente continuada, em razão de seu público já atuar na docência, enquanto que o público de nossa pesquisa ainda se encontrava em estado de formação inicial. Ambos os trabalhos (DINIS; CAVALCANTE, 2008; COSTA; RIBEIRO, 2011), resultantes de pesquisas também recentes e com o mesmo objeto (formação em Pedagogia) e proposta (o que pensam sobre gênero) de investigação, decerto ampararam a presente produção.

Outras duas produções consultadas acabaram por também apresentar essa função de amparo pela sua pertinência e similaridade investigativa, as quais se trataram de Marília Pinto de Carvalho (2011), que discute diferentes conceitos de gênero fornecidos por autoras(es) citadas(os) em trabalhos apresentados nas reuniões nacionais da Associação Nacional de Pós-Graduação e Pesquisa em Educação (ANPEd) de 1999 a 2009; e de Maria Eulina Pessoa de Carvalho e Glória Rabay (2015), que problematiza as incompreensões de gênero geradas pelo seu uso em diversos contextos.

Da composição deste artigo, primeiro descrevemos a metodologia de nossa investigação empírica, no que tange ao processo de elaboração e aplicação do questionário. Também tratamos da pergunta aberta selecionada, dentre as várias que compuseram o questionário, que resultou numa profícua revisão do conceito de gênero com base nas concepções das(os) participantes ora apresentada, resgatando conceitos presentes tanto na literatura de gênero feminista quanto no cotidiano dessas pessoas.

Ressalta-se, com base nos resultados obtidos com a análise dos dados coletados com o questionário, que as concepções das(os) graduandas $(\mathrm{os})$ respondentes $(\mathrm{n}=109)$ sobre o conceito de gênero distribuíram-se em cinco principais conceitos: em concepção 1) polissêmica; 2) biologizante e religiosa; 3) funcionalista; 4) identitária; e 5) associada à sexualidade. A consulta e fundamentação na literatura em questão - que se apresenta à medida que se discute essas concepções encontradas -, em meio à profusão e heterogeneidade teórica da produção feminista do campo dos Estudos de Gênero, foi guiada de acordo com a demanda dos conceitos evidenciados nas concepções das(os) participantes, ainda que alguns desses conceitos evidenciados requereram fundamentação em produções de outra literatura do campo, cujas perspectivas teóricas não são consideradas feministas no estudo de gênero.

\section{METODOLOGIA: ELABORAÇÃO E APLICAÇÃO DE INSTRUMENTO, AMOSTRAS E FORMAS DE ANÁLISE}

Como recorte de uma investigação empírica que, considerando seu todo, consistiu em um trabalho de campo maior, delimitamos este artigo para exposição dos resultados obtidos com um dos instrumentos utilizados: o questionário aberto. A elaboração desse questionário durante a pesquisa foi feita com base em quatro procedimentos: com base nos 1) resultados obtidos em duas sessões de grupo focal com graduandas(os) do mesmo curso que ambientou a pesquisa, momento precedente do trabalho de campo; na 2) literatura consultada dos temas abordados pelo instrumento, gênero e sexualidades; 3) nos questionamentos de dois juízes de instrumento; e na 4) aplicação de um teste piloto do questionário. 
Só depois de finalizados os quatro procedimentos desse momento preliminar do trabalho de campo, deu-se início à aplicação do questionário.

Como já ressaltado, o questionário foi composto por perguntas abertas e dilemas morais para coleta e, por conseguinte, análise do processo formativo investigado tanto no plano abstrato - o que pensam sobre as temáticas de gênero e sexualidades -, que aqui corresponde à categoria concepções; quanto no plano da disposição para a ação - como agiriam diante da diversidade sexual e de gênero -, compreendido pela categoria condutas. A criação das perguntas e dilemas teve como referência, além da etapa precedente de grupos focais ${ }^{7}$, a literatura, iminentemente feminista, consultada dos temas abordados pelo instrumento.

Todavia, Daniel Abud Seabra Matos e José Rubens Lima Jardilino (2016, p. 23, grifos nossos) apontam que:

\begin{abstract}
Nas pesquisas sobre $o$ que pensam alunos, professores e outros atores educacionais, uma enorme variedade de termos tem sido usada para se referir às representações mentais. Encontramos termos como: concepções, conceitos, crenças, imagens, metáforas, percepções, orientações, perspectivas, categorias, construtos, conhecimentos, culturas, repertórios, teorias, representações, dentre outros. [...] essa diversidade de vocábulos acaba dificultando a compreensão de pesquisas da área educacional e seu arcabouço teórico-conceitual.
\end{abstract}

Ao elegermos as três categorias, conhecimentos, concepções e condutas, em nossa metodologia, consideramos os esclarecimentos trazidos pelos autores (2016). Verificamos, em revisão própria da literatura, que as pesquisas que utilizam dessas três categorias, de fato, não são claras sobre o que entendem por elas e, assim, não fornecem conceitos que podem sustenta-las no âmbito de sua investigação, fazendo-se o uso do conceito genérico que é evocado pela palavra. Como autocrítica, essa falta de rigor teórico-metodológico está presente, até mesmo, em algumas pesquisas anteriores desenvolvidas e orientadas nos Núcleos e Grupos de Pesquisa que integramos.

Portanto, em nossa investigação, atribuímos um conceito próprio a cada uma das categorias que utilizamos, respaldando-as com um determinado referencial da abordagem qualitativa de pesquisa (Menga LÜDKE; Marli ANDRÉ, 1986) no qual nos aprofundamos: a Hermenêutica - embora não incluamos aqui uma discussão mais completa pelos limites deste texto. Definida como a teoria ou filosofia da interpretação dos sentidos, reconhecendo-se na "[...] percepção de que as expressões humanas contêm componente significativo, que tem que ser reconhecido como tal, por um sujeito e transposto para o seu próprio sistema de valores e significados" (Josef BLEICHER, 2002, p. 13), as três categorias se inserem nesse campo de interpretação de sentidos, no que tange à investigação da atribuição de significados e geração de conceitos pelas pessoas em sua cultura.

Então conceituando essas categorias, argumentamos que as disposições da(o) professora(o), isto é, suas possíveis práticas, a ação que desempenhará, são precedidas pelas concepções que essa(e) mantém sobre o conteúdo a ser trabalhado. É a partir de uma concepção prévia, que se constitui pelos vários tipos de conbecimentos que a(o) docente teve contato durante sua formação profissional e pessoal, que sua prática (referente à categoria condutas) enquanto educadora ou educador se materializa.

Maewa Martina Gomes da Silva e Souza (2010, p. 14) corrobora dessa ideia ao ressaltar que são as concepções de uma pessoa as responsáveis por produzirem "[...] diferentes formas de tratamento aos indivíduos[, ] cada conceito designa uma prática diferenciada, o que nos leva a perceber como uma definição, uma concepção permeia uma prática, um estilo de vida", sendo um dos poucos trabalhos que encontramos que conceitua a categoria concepçôes à qual faz uso. Assim, quanto mais a concepção da(o) docente sobre gênero for constituída por conhecimentos científicos emancipatórios - no caso, provindo de uma ciência com projeto emancipatório preferencialmente feminista (Sandra HARDING; 1986; Conceição NOGUEIRA; 2017) -, mais chances sua conduta, então oriunda dessa concepção, tem em ser satisfatória no tratamento da diversidade sexual e de gênero na escola e no desenvolvimento de um trabalho que aborde a temática.

\footnotetext{
${ }^{7}$ Não cabe aqui discutir os resultados encontrados com a aplicação das duas sessões de grupo focal e os especificar pormenoramente sobre como subsidiaram a elaboração do questionário. Porém, a critério de consulta, parte desses resultados se encontram publicados em (Matheus Estevão Ferreira da SILVA, 2019). 
Para contemplar essas categorias, o questionário foi composto com o total de 18 perguntas abertas e 03 dilemas morais. Com o questionário elaborado, antes de sua aplicação, corroborou-se com as sugestões de Marina de Andrade Marconi e Eva Maria Lakatos (2003, p. 203) acerca da avaliação do instrumento por juízes e da realização de um pré-teste: "depois de redigido, o questionário precisa ser testado antes de sua utilização definitiva, aplicando-se alguns exemplares em uma pequena população escolhida". Realizamos, primeiramente, um teste piloto com cinco graduandas(os) do mesmo curso, mas que não participariam da pesquisa em nenhum outro momento - tal como as(os) participantes dos grupos focais -, selecionando-as(os) por meio de amostra aleatória (Antonio Carlos GIL, 2008).

Em seguida ao pré-teste, dispôs-se da avaliação do questionário por dois juízes, uma pesquisadora e um pesquisador atuantes nos temas abordados pelo instrumento e com experiência no trabalho com dilemas morais em pesquisa. Com ambos procedimentos, viu-se que o questionário seguia e contemplava seu propósito no cumprimento dos objetivos da pesquisa. Assim, com a elaboração do instrumento finalmente concluída, deu-se prosseguimento à sua aplicação.

A aplicação foi feita no curso de Pedagogia de uma universidade pública paulista, curso escolhido por critério de conveniência. Já as(os) participantes foram selecionados por meio da amostragem de etapas, que: "[...] pode ser utilizada quando a população se compõe de unidades que podem ser distribuídas em diversos estágios" (GIL, 2008, p. 93). A partir da amostragem de etapas, elegeram-se para participação na pesquisa: as três turmas do primeiro ano (ingressantes) e as três do quarto ano (concluintes), uma do período matutino e duas do período noturno respectivamente, o que atribuiu à investigação o desenho transversal de pesquisa.

Os questionários preenchidos foram recolhidos e, após a transcrição das respostas em um material textual que gerou nosso corpus de análise, verificamos o total de 165 questionários válidos, totalizando uma amostra de 165 sujeitos $(\mathrm{N}=165)$, parte das(os) 120 estudantes matriculadas(os) no primeiro ano e as(os) 120 no quarto ano do curso.

No questionário, antes das perguntas abertas e dos dilemas morais, havia ainda algumas perguntas fechadas para caracterização do sujeito respondente, na identificação das variáveis da amostra da pesquisa. Para contabilização dessas variáveis, as respostas dadas a tais perguntas de caracterização foram transcritas para uma planilha gerada pelo software SPSS C) (STATISTICAL PACKAGE FOR THE SOCIAL SCIENCES, 2017), e a contabilização das variáveis que consideramos principais foi disposta na tabela 1.

Em nossa pesquisa, as temáticas de gênero e sexualidades foram tratadas como conteúdo, isto é, como um conjunto de saberes formados e acumulados historicamente pela humanidade e que pode ser adquirido pelas pessoas de forma a compor seu patrimônio intelectual. Essa observação se faz necessária devido a outra possibilidade de tratar ambas as temáticas: como perspectiva (Leonardo LEMOS DE SOUZA, 2017). Gênero e sexualidades como perspectiva, em síntese, referem-se ao modo como as temáticas se inserem na vida e nos corpos das pessoas. Assim, além de conteúdo, elas tornam-se também marcadores sociais (ou variáveis, tratando-as para fins estatísticos), isto é, referem-se a manifestações de características e de construções sociais nos sujeitos que se interseccionam e se hierarquizam em diferentes culturas (NOGUEIRA, 2017). Os sujeitos podem ser marcados tanto pelo gênero, marcados como homens ou mulheres, cisgêneros ou transgêneros em geral, e não-binários; quanto pela sexualidade, marcados como heterossexuais, homossexuais ou bissexuais .

Em pesquisa, ao invés de um tratamento das representações mentais em sentido genérico, o que pensam, como ocorre com gênero e sexualidades como conteúdo - e como aqui fizemos -, uma investigação que as tratam como perspectiva se direcionaria para quem pensa o quê? Então, mesmo considerando as variáveis dos sujeitos participantes, nosso foco neste texto é o que eles pensam sobre o gênero enquanto conteúdo, sendo o gênero como perspectiva uma proposta para outra produção.

\footnotetext{
${ }^{8}$ Utilizamos dessa nomenclatura cientes de sua insuficiência em contemplar as inúmeras expressões de identidade de gênero e orientação sexual. Tal nomenclatura aglutina as possibilidades identitárias em grupos identitários restritos, conforme questionam as perspectivas queer e pós-estruturalista da literatura de gênero feminista acerca do binarismo de gênero e da coerência e pertencimento a determinada identidade que se mostre inteligivel (BUTLER, 2007; Matheus Estevão Ferreira da SILVA; Tânia Suely Antonelli Marcelino BRABO, 2016).
} 
Tabela 1 - Caracterização da amostra respondente do questionário

\begin{tabular}{|c|c|c|}
\hline & Variáveis & N. ${ }^{\circ}$ de participantes \\
\hline \multirow{21}{*}{$\begin{array}{l}\text { É orientado } \\
\text { gênero }\end{array}$} & \multirow{11}{*}{ desenvolve pesquisa sobre } & $92(55,7 \%)$ ingressantes \\
\hline & & $73(44,3 \%)$ concluintes \\
\hline & & $156(94,5 \%)$ feminino \\
\hline & & $9(5,5 \%)$ masculino \\
\hline & & $60(36,4 \%)$ matutino \\
\hline & & $105(63,6 \%)$ noturno \\
\hline & & $3(1,8 \%) \operatorname{sim}$ \\
\hline & & $162(98,2 \%)$ não \\
\hline & & $17(12,9 \%)$ Cristã \\
\hline & & 58 (43,9\%) Católica \\
\hline & & $31(23,5 \%)$ Evangélica \\
\hline & \multirow[t]{6}{*}{ Religião } & $6(4,5 \%)$ Espírita \\
\hline & & $1(0,8 \%)$ Mórmon \\
\hline & & $1(0,8 \%)$ Umbandista \\
\hline & & 7 (5,3\%) Agnóstica \\
\hline & & $11(8,3 \%)$ Ateísta \\
\hline & & $4(3,0 \%)$ Amarela \\
\hline & \multirow[t]{3}{*}{ Raça-etnia } & $73(54,9 \%)$ Branca \\
\hline & & $46(34,6 \%)$ Parda \\
\hline & & $10(7,5 \%)$ Preta \\
\hline & Total & $165(100 \%)$ \\
\hline
\end{tabular}

Fonte: Dados da pesquisa

Legenda: A tabela apresenta a caracterização da amostra de nossa pesquisa, segundo as variáveis que consideramos principais, sendo elas: ano de matrícula $(55,7 \%$ ingressantes e $44,3 \%$ concluintes), gênero ( $94,5 \%$ feminino e 5,5\% masculino), período ( $36,4 \%$ matutino e $63,6 \%$ noturno), se pesquisa sobre gênero (1,8\% sim e 98,2\% não), religião (12,9\% Cristã, 43,9\% Católica, 23,5\% Evangélica, 4,5\% Espírita, 0,8\% Mórmon, 0,8\% Umbandista, 5,3\% Agnóstica e 8,3\% Ateísta) e raça-etnia (3,0\% Amarela, 54,9\% Branca, 34,6\% Parda, 7,5\% Preta).

Com a caracterização da amostra respondente do questionário $(\mathrm{N}=165)$, identificamos que esse público da pesquisa foi majoritariamente feminino ( $n=156 ; 94,5 \%)$, tendo em vista a consolidação do curso de Pedagogia como um espaço exclusivamente feminino na história da docência no Brasil, conforme argumenta Tânia Suely Antonelli Marcelino Brabo (2005) sobre o processo de feminização do magistério. Também majoritariamente foram as(os) participantes matriculadas(os) no período noturno $(\mathrm{n}=105 ; 63,6 \%)$, devido ao maior número de turmas do noturno em contraponto às matutinas ( $\mathrm{n}=60$; $36,4 \%$ ), e no primeiro ano do curso ( $\mathrm{n}=92 ; 55,7 \%$ ), em razão da maior adesão à pesquisa das(os) ingressantes do que das(os) concluintes.

Segundo a variável religiosidade, a maioria da amostra apresenta transcendência, vinculandose ao Cristianismo ( $\mathrm{n}=113 ; 85,6 \%)$, mas com todas as vertentes dessa religião, que foram citadas pelos sujeitos, incluídas nesse dado, como pode-se observar na Tabela 1. Em menor número esboçaram-se a transcendência Agnóstica ( $\mathrm{n}=7 ; 5,3 \%$ ) e a não transcendência, ou seja, o Ateísmo ( $\mathrm{n}=11 ; 8,3 \%$ ). Já em relação à variável de raça-etnia, a maioria se autodeclarou branca $(n=73 ; 54,9 \%)$ e parda $(n=46 ; 34,6 \%)$.

Por fim, sobre as formas de análise empregues nos dados coletados pelo questionário, para sua organização e interpretação, além de termos como base a literatura de gênero feminista, cujas(os) autoras(es) consultadas(os) serão evidenciadas(os) à medida em que se discutem as concepções encontradas, fizemos o uso de técnicas de análise específicas de acordo com a necessidade evidenciada em cada pergunta do instrumento elaborado. Como já mencionado, delimitamos a exposição deste texto 
para apenas o plano abstrato do processo formativo investigado, isto é, das concepções das(os) participantes colhidas pelas perguntas abertas, e, ainda mais especificamente, para a pergunta de número 03 do questionário: “O que você compreende por gênero? Ou seja, o que é gênero para você?”. Nessa pergunta, assim como na maioria das perguntas abertas, empregamos a técnica de análise categorial da Análise de Conteúdo (AC) (Lawrence BARDIN, 2016).

Bardin (2016, p. 14) define a AC como um conjunto de técnicas de análise, no plural, “[...] das comunicações, que utiliza procedimentos sistemáticos e objetivos de descrição do conteúdo das mensagens". Dessa pluralidade de técnicas que constitui a Análise de Conteúdo, utilizamos daquela que é denominada de análise categorial. Com ela, seguindo-se sistematicamente seus procedimentos, pudemos identificar os significados atribuídos pelas(os) participantes ao conceito de gênero, gerando-se cinco categorias criadas a partir de indicadores, sendo escolhidos os do tipo tema, extraídos de nosso corpus de análise.

Assim, cada uma das cinco categorias geradas por meio da AC referiu-se a uma concepção diferente das(os) graduandas(os) sobre o conceito de gênero, com sua identificação respaldando-se na produção da literatura consultada. Devido ao número considerável de sujeitos participantes da pesquisa, por conseguinte, de uma amostra de tamanho amplo para uma técnica qualitativa como essa, calculamos também a frequência de evocação de cada categoria pela amostra. Caracterizada nossa metodologia e o trabalho de campo realizado, prosseguiremos agora para a exposição das análises e resultados obtidos com a pergunta selecionada do questionário junto aos sujeitos participantes do curso de Pedagogia.

\section{GÊNERO NA POLISSEMIA DA PALAVRA}

A pergunta que interrogava a(o) respondente sobre o conceito de gênero foi inserida no questionário por apresentar grande relevância para nossa pesquisa, visto que, na análise da formação em Pedagogia, é a concepção dessa(e) profissional que subsidiará sua futura atuação docente no contexto escolar junto à própria temática de gênero e ao público da diversidade que a protagoniza. Contudo, hoje ostentando um conceito constantemente debatido e ressignificado, a inserção de gênero em diferentes propostas na formação docente e, mais do que isso, a sua compreensão nos cursos de formação, ainda são vistas como um desafio, conforme discutem pesquisas recentes (UNESCO, 2015; SILVA; BRABO; MORAIS, 2017).

E por esses debates e ressignificação, que permanecem em aberto, seria mais adequado falar em conceitos de gênero, no plural, dada a variedade de significados que são atribuídos à palavra gênero contemporaneamente. Nesse sentido, a primeira categoria que representou as concepções das(os) graduandas(os) sobre o conceito de gênero, a qual identificamos com base na técnica de AC e na literatura pertinente, foi intitulada de Gênero na polissemia da palavra. No quadro a seguir, retratamos essa categoria, constituída a partir dos indicadores extraídos das respostas dadas pelas(os) participantes, também retratados (alguns deles) no quadro 1.

Com base no Quadro 1, observa-se que do total de participantes da pesquisa $(\mathrm{N}=165)$, apenas 109 sujeitos responderam à pergunta em questão. Na concepção retratada, indicadores extraídos das respostas de 20 sujeitos vieram a constituílla, sendo eles 18,34\% do total de respondentes. Essa concepção de gênero aponta para a pluralidade conceitual que atualmente a palavra ostenta, isto é, para sua polissemia, como uma palavra ambígua, com mais de um significado e contexto de uso, em razão da ampla trajetória histórica no desenvolvimento de sua significação. Porém, ao mesmo tempo que se aponta para tal polissemia, ressalta-se também o significado inicial atribuído a gênero e que se mantem comum a quase todos os conceitos de gênero mais hodiernos, então antecedendo-os: a classificação.

O significado de classificação no gênero está presente desde sua etimologia. A palavra gênero possui raízes na base indo-europeia: gen- ou gnê- que significam nascer e gerar. Mais adiante, com a origem da língua latina, estende-se do latim genus, -eris, que significa nascimento, descendência, origem, raşa e linhagem (Antonio Geraldo da CUNHA, 1982). Indícios dessas raízes classificatórias ficam evidentes na argumentação dos sujeitos 71 e 125. 
Quadro 1 - Categoria representativa à concepção polissêmica de gênero das(os) participantes sobre o conceito de gênero

\begin{tabular}{|c|c|}
\hline Categoria & Indicadores \\
\hline \multirow{3}{*}{$\begin{array}{l}\text { 1. Gênero na polissemia } \\
\text { da palavra: o termo }\end{array}$} & Sujeito 29 - Gêneros como o musical, cultural, etc. \\
\hline & Sujeito 42 - Conjunto que se acha ligado por uma mesma origem. \\
\hline & Sujeito 43 - São coisas similares, da mesma origem. \\
\hline \multirow{4}{*}{$\begin{array}{l}\text { gênero evoca mais de um } \\
\text { conceito, é uma palavra } \\
\text { polissêmica, apresenta mais } \\
\text { de um significado, mas } \\
\text { detém sua significação } \\
\text { primária classificatória, } \\
\text { refere-se à classificação de }\end{array}$} & $\begin{array}{l}\text { Sujeito } 48 \text { - Gênero é uma particularidade, uma característica que } \\
\text { une um determinado grupo/conjunto. }\end{array}$ \\
\hline & $\begin{array}{l}\text { Sujeito } 71 \text { - Gênero, tem várias significações, mas é algo } \\
\text { diferente, o que diferencia um do outro, etc. }\end{array}$ \\
\hline & $\begin{array}{l}\text { Sujeito } 98 \text { - Conjunto de seres, ligados pela mesma origem ou } \\
\text { similar de uma particularidade. }\end{array}$ \\
\hline & Sujeito 125 - Gênero é uma forma de classificar algo. \\
\hline \multirow{2}{*}{ 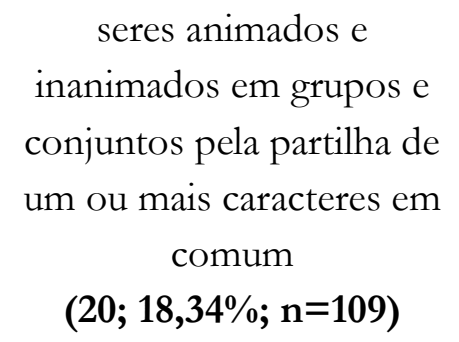 } & $\begin{array}{l}\text { Sujeito } 142-\text { É a diversidade de opções. Na gramática } \\
\text { compreendo gênero por diversos tipos textuais e nas relações } \\
\text { sociais compreendo gênero por opções sexuais (homem, mulher, } \\
\text { gay, lésbica, trans, etc.). }\end{array}$ \\
\hline & $\begin{array}{l}\text { Sujeito } 144 \text { - Tanto na questão humana quanto na questão textual } \\
\text { (gêneros do discurso) gênero é uma denominação a "escolhas". }\end{array}$ \\
\hline
\end{tabular}

Fonte: Dados da pesquisa

Legenda: $O$ quadro apresenta a primeira categoria identificada representativa às concepções das(os) participantes sobre o conceito de gênero, intitulada Gênero na polissemia da palavra, junto aos indicadores extraídos das respostas que geraram essa categoria. A categoria foi formada a partir dos indicadores de 20 dos 109 sujeitos que responderam à pergunta de número 3 do questionário, o que concerniu a $18,34 \%$ dessa amostra.

Segundo Ana Lúcia Furquim Campos-Toscano (2009, p. 22), a etimologia traz a “[...] reiteração de termos como 'categoria', 'classificação', 'divisão', 'características', 'estilo', denota que o conceito de gênero não ultrapassa a noção de espécie, ficando, portanto, inscrito como uma categoria de classificação de traços comuns". Logo, chama-se de gênero o grupo resultante de tal seleção por caracteres comuns. E a datar do período da Antiguidade greco-latina, gênero passa a ser utilizado para classificação de obras artísticas, em que se encontram os gêneros musicais, literários, poéticos, teatrais, etc., perpetuando-se ao longo dos tempos, a qual se fez presente na argumentação do sujeito 29.

De acordo com Armando Plebe (1978) e Carvalho (2011), no âmbito da linguagem e da gramática, as palavras também passaram a ser classificadas, a partir dos estudos do filósofo grego Protágoras de Abdera, em três gêneros: como femininas, masculinas e neutras. Sobre esse último, Dante Lucchesi (2009, p. 295) esclarece que na "[...] formação das línguas românicas, verifica-se a passagem de um sistema tripartido encontrado no chamado latim clássico para um sistema fundado na oposição entre o masculino e o feminino, com o desaparecimento do neutro".

Por meio da classificação na linguagem, expressa pela oposição feminino-masculino, gênero adquiriu um outro significado, dando origem a um novo conceito: de sinonímia ao sexo biológico. Esse conceito também se fez presente nas compreensões da amostra da pesquisa, o qual é explorado mais adiante.

Vale ressaltar que não necessariamente a concepção sobre gênero de um sujeito abrange apenas um único conceito dos vários atribuídos a gênero, ou seja, enquadra-se somente em uma das categorias que identificamos, conforme ilustra a argumentação na íntegra do sujeito 142 que dispôs de dois indicadores, inserida propositalmente no Quadro 1. A concepção desse sujeito, por exemplo, 
encontra-se vinculada à presente categoria, do conceito polissêmico de gênero, e na categoria que associa gênero ao desejo sexual, a qual também discutiremos mais adiante.

\section{GÊNERO EM CONCEPÇÃO BIOLÓGICA, COMO SINONÍMIA DE SEXO E FREQUENTE ASSOCIAÇÃO AO DISCURSO RELIGIOSO}

Enquanto na primeira concepção de gênero identificada admite-se sua pluralidade conceitual, porém apontando para o significado inicial e quase comum de classificação que dispõe, a concepção seguinte referiu-se a um conceito de gênero em específico: para os sujeitos que detêm essa concepção, gênero é o mesmo que sexo. Indicadores extraídos das respostas de 30 sujeitos, sendo $27,52 \%$ do total de respondentes, geraram a categoria representativa dessa concepção, a qual foi intitulada de Gênero em concepşão biológica, como sinonímia de sexo e frequente associação ao discurso religioso.

Os estudos sobre as diferenças sexuais entre mulheres e homens surgiram a partir do final do século XVIII, primeiro exclusivamente sob a abordagem biológica da Ciência positivista, os quais posteriormente assentariam o conceito moderno de sexo. Segundo Fabíola Rohden (2003, p. 201), a partir desses estudos, a diferença sexual "passa a ser considerada como natural e imutável pela ciência. Essa ênfase na naturalidade estaria relacionada com as transformações ocorridas a partir do fim do século XVIII [...] que requeriam mudanças nas relações de gênero estabelecidas".

Do ponto de vista biológico, as diferenças entre mulheres e homens são medidas por intermédio da categoria sexo, a qual os seres vivos são classificados: como do sexo masculino, sexo feminino ou intersexuais, de acordo com o conjunto de características estruturais e funcionais que seus corpos apresentam, referindo-se, principalmente, à produção de gametas, aos aparelhos reprodutores e aos caracteres sexuais secundários decorrentes de hormônios. Essa conceituação de sexo é atribuída ao gênero, por exemplo, pelos sujeitos 31 e 63, como mostra o quadro 2.

Quadro 2 - Categoria representativa à concepção biologizante e religiosa de gênero das(os) participantes sobre o conceito de gênero

\begin{tabular}{|c|c|}
\hline & \\
\hline \multirow{9}{*}{$\begin{array}{l}\text { 2. Gênero em concepção } \\
\text { biológica, como sinonímia } \\
\text { de sexo e frequente } \\
\text { associação ao discurso } \\
\text { religioso: gênero e sexo são } \\
\text { sinônimos ou o gênero, } \\
\text { como identidade, é definido } \\
\text { pelo sexo de nascimento, } \\
\text { manifestando-se conforme } \\
\text { determinado biologicamente, } \\
\text { usa-se o determinismo } \\
\text { biológico com frequente } \\
\text { associação ao discurso } \\
\text { religioso cristão para sua } \\
\text { legitimação, funde-se o } \\
\text { discurso biológico ao } \\
\text { religioso } \\
\mathbf{( 3 0 ;} \mathbf{2 7 , 5 2} \% \mathbf{n}=\mathbf{1 0 9})\end{array}$} & $1 C^{\wedge}{ }^{\prime}$ \\
\hline & \\
\hline & 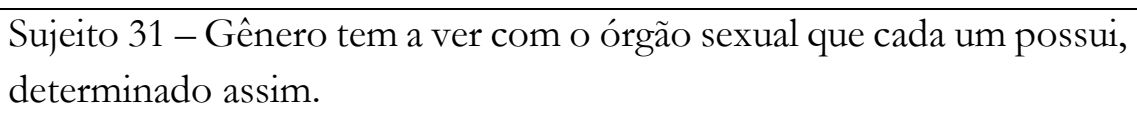 \\
\hline & \\
\hline & $\begin{array}{l}63-G \hat{e} \\
\text {, se ele al }\end{array}$ \\
\hline & $\begin{array}{l}\text { Sujeito } 64-\text { No ponto } \\
\text { sexo pelo qual o bebé é }\end{array}$ \\
\hline & $\begin{array}{l}\text { Sujeito } 73 \text { - Ligo gế } \\
\text { características de nos }\end{array}$ \\
\hline & $\begin{array}{l}\text { o } 95-\text { Gêr } \\
\text { sexo da fo }\end{array}$ \\
\hline & $\begin{array}{l}\text { Sujeito } 157 \text { - Gênero é quando você nasce se nascer com o órgão } \\
\text { masculino você é do gênero masculino, se nascer com o órgão } \\
\text { feminino você é do gênero feminino. }\end{array}$ \\
\hline
\end{tabular}

Fonte: Dados da pesquisa

Legenda: $\mathrm{O}$ quadro apresenta a segunda categoria identificada representativa às concepções das(os) participantes sobre o conceito de gênero, intitulada Gênero em concep̧̧ão biológica, como sinonímia de 
sexo e frequente associação ao discurso religioso, junto aos indicadores extraídos das respostas que geraram essa categoria. A categoria foi formada a partir dos indicadores de 30 dos 109 sujeitos que responderam à pergunta de número 3 do questionário, o que concerniu a 27,52\% dessa amostra.

Nessa concepção, conforme retrata o Quadro 2, admite-se apenas a biologia dos corpos como definidora da identidade humana, negando-se qualquer outra variável, inclusive a da construção social, que pudesse, juntamente à biologia, exercer influência sobre o ser homem e o ser mulher. Não obstante, segundo essa concepção biologizante, até as relações sociais estabelecidas entre mulheres e homens são decorrentes de suas diferenças sexuais, como vê-se nos indicadores dos sujeitos 24 e 157, de forma implícita, mas ainda assim observável em suas argumentações.

Para Guacira Lopes Louro (1997, p. 21) "Seja no âmbito do senso comum, seja revestido por uma linguagem 'científica', a distinção biológica, ou melhor, a distinção sexual, serve para compreender - e justificar - a desigualdade social”. Trata-se, portanto, de uma concepção de gênero genuinamente determinista (inatista), importada do conceito moderno de sexo e vinculada ao determinismo biológico: baseando-se na crença de que a fisiologia e todo o aparato biológico sexual são responsáveis pela maneira como mulheres e homens se relacionam, distribuem-se e atuam em sociedade, justificando aspectos (que, na verdade, são) históricos e culturais, o que é muito sugestivo sobre como os sujeitos, cujos indicadores deram origem a esta categoria, concebem as relações de gênero e o público da diversidade sexual e de gênero.

Em alguns dos indicadores, no entanto, como é o caso do sujeito 95 e também de indicadores que não apareceram no Quadro 2, a concepção biológica foi relacionada com postulados da religiosidade cristã. Por partirem de ideais deterministas, embora com suas fontes incongruentes entre si (o método científico positivista e as chamadas escrituras sagradas), fundiu-se o discurso biológico ao religioso apenas para legitimação do binarismo identitário mulher e homem. O que deveria ser uma amálgama impossível, aqui fez-se possível, como também se tem encontrado no discurso de setores que recentemente promovem a narrativa "ideologia de gênero" (Jimena FURLANI, 2016b; SILVA; BRABO; MORAIS, 2017) e, por meio disso, a desinformação sobre o tema gênero, deslegitimando e ridicularizando o tema e os sujeitos que o protagonizam.

Cabe ressaltar que a "ideologia de gênero" foi criada por setores da Igreja Católica e pelo movimento (inter)nacional autointitulado "Movimento Pró-Vida e Pró-Família" e que se sustenta em "em confusões teóricas e usos inadequados dos estudos de gênero, equívocos intencionais e meticulosamente calculistas da trajetória de desenvolvimento conceitual do tema e da real literatura que o estabelece" (SILVA; BRABO; MORAIS, 2017, p. 1268). Ela tem como premissa criminalizar e "destinar ao inferno" qualquer manifestação de gênero que não esteja de acordo com os seus postulados de origem religiosa. Assim, o que deveria ser de âmbito privado (opção por orientar a própria vida por preceitos religiosos), tem sido reenvidado pelas(os) que a promovem como sendo de âmbito público (obrigar que todos sigam tais preceitos, até mesmo incluindo-os em políticas públicas e os utilizando como argumento para barrar políticas que não estejam de acordo com eles).

Nesse sentido, essa narrativa foi incorporada fortemente durante o episódio de retirada dos termos gênero e orientação sexual dos Planos de Educação, desde Municipais, Estaduais e Nacional, especialmente por parlamentares ligadas(os) a setores conservadores e religiosos, e parece estar intimamente relacionada com as respostas dos sujeitos que constituíram a presente concepção de gênero. Para essa narrativa, gênero é definido pelo sexo biológico, o que se respaldaria nas escrituras sagradas cristãs (então misturando postulados biológicos e religiosos), e qualquer variância disso seria caracterizada como um desvio, um ato profano, ao mesmo tempo em que se nega, desvirtua e ridiculariza as contribuições dos Estudos de Gênero, sobretudo as de orientação feminista, para a compreensão da questão da diversidade de gênero.

\section{GÊNERO PRÓXIMO A SUA CONCEPÇÃO ACADÊMICA CLÁSSICA FUNCIONALISTA}

A categoria representativa seguinte foi constituída a partir dos indicadores das respostas de 37 sujeitos, sendo 33,94\% do total de respondentes, denominando-a de Gênero próximo a sua concepção 
acadêmica clássica funcionalista. Das concepções expostas neste artigo, essa é a que mais se alinha com a perspectiva que defendemos, sendo ela a feminista, para fundamentar a formação em gênero das(os) docentes responsáveis pela educação escolar, devido ao seu caráter potencialmente emancipatório e crítico. Apesar de alinhar-se, não corresponde, de fato, à perspectiva que defendemos, visto que a simples distinção entre a biologia e o social, cerne desta concepção de gênero, “[...] está relativamente simplificada para dar conta das diferentes possibilidades do debate feminista atual” (NOGUEIRA, 2017, p. 47).

\section{Quadro 3 - Categoria representativa à concepção funcionalista de gênero das(os) participantes sobre o conceito de gênero}

\begin{tabular}{|c|c|}
\hline Categoria & Indi \\
\hline \multirow{7}{*}{$\begin{array}{l}\text { 3. Gênero próximo a sua } \\
\text { concepção acadêmica clássica } \\
\text { funcionalista: gênero é uma } \\
\text { construção social polarizada em } \\
\text { um binarismo identitário, } \\
\text { feminino e masculino, é formado } \\
\text { cultural e historicamente com } \\
\text { base nas diferenças sexuais } \\
\text { observáveis entre os sujeitos, } \\
\text { trata-se de uma } \\
\text { complementariedade ao sexo } \\
\text { natural das pessoas, gênero é o } \\
\text { social e sexo é o biológico } \\
(\mathbf{3 7} ; \mathbf{3 3 , 9 4 \%} \mathbf{n}=\mathbf{1 0 9})\end{array}$} & $\begin{array}{l}\text { Sujeito } 6 \text { - Gênero é o que identifica e diferencia os homens e as } \\
\text { mulheres, gênero masculino e gênero feminino. }\end{array}$ \\
\hline & $\begin{array}{l}\text { Sujeito } 50 \text { - Gênero é uma construção social. É uma categoria forjada } \\
\text { social e culturalmente para fazer o que se chama de "feminino" e } \\
\text { "masculino". }\end{array}$ \\
\hline & Sujeito 60 - Gênero é a posição social que você se encontra. \\
\hline & $\begin{array}{l}\text { Sujeito } 65 \text { - Combinado social de acordo com as características físicas } \\
\text { que estabelecem diferença entre si. }\end{array}$ \\
\hline & $\begin{array}{l}\text { Sujeito } 102 \text { - Gênero é o que define o feminino e o masculino, porém } \\
\text { acredito que isso é uma construção social. Desde pequenos somos } \\
\text { levados a seguir um dos lados e isso e dá pelo sexo que nascemos. }\end{array}$ \\
\hline & $\begin{array}{l}\text { Sujeito } 124 \text { - Gênero é a definição que se dá pela sociedade do que é } \\
\text { correto segundo ela por homem e mulher. }\end{array}$ \\
\hline & $\begin{array}{l}\text { Sujeito } 126 \text { - É a definição que a sociedade impõe segundo o que ela } \\
\text { acha correto sobre o homem e a mulher. }\end{array}$ \\
\hline
\end{tabular}

Fonte: Dados da pesquisa

Legenda: $\mathrm{O}$ quadro apresenta a terceira categoria identificada representativa às concepções das(os) participantes sobre o conceito de gênero, intitulada Gênero próximo a sua concepsão acadêmica clássica funcionalista, junto aos indicadores extraídos das respostas que geraram essa categoria. A categoria foi formada a partir dos indicadores de 37 dos 109 sujeitos que responderam à pergunta de número 03 do questionário, o que concerniu a 33,94\% dessa amostra.

Segundo Tânia Suely Antonelli Marcelino Brabo (2015, p. 111), o Feminismo pode ser caracterizado tanto como "[...] um movimento social, com uma ideologia de libertação das mulheres, quanto uma teoria crítica do sexismo (discriminação de sexo baseada na ideologia da inferioridade da mulher), da visão androcêntrica de mundo e da dominação masculina". No início da década de 1970, estudos acadêmicos de orientação feminista institucionalizavam-se nas Universidades em escala global, juntamente ao estabelecimento conceitual de uma categoria que distinguia natureza de cultura, aspectos da vida e do corpo de mulheres e homens de origem biológica em oposição a aspectos de origem social, respectivos aos domínios do sexo biológico e do - que passou a se denominar - gênero. Como mostra o Quadro 3, a compreensão sobre essa distinção fica evidente nas argumentações dos sujeitos 65 e 102.

O conceito de gênero ali estabelecido referia-se às construções sociais frente ao ser mulher e o ser homem, convencionadas cultural e historicamente, a partir das diferenças sexuais de mulheres e homens, o que polarizou as identidades humanas em um binarismo intransigível e possibilitou a difusão do determinismo biológico, até mesmo revestido pelo discurso científico moderno, que naturalizava essas construções sociais. Com origens na Antropologia das décadas de 1930 e 1940, contudo, com sua ideia central erigida na obra de 1949, O segundo sexo, de Simone de Beauvoir: "Ninguém nasce mulher, torna- 
se mulher [...]" (BEAUVOIR, 2016, p. 11), o gênero foi aderido pelas teorizações do e pelo Movimento Feminista, nas mais variadas vertentes teóricas e políticas que coexistem (Feminismo Liberal, Feminismo Marxista, Feminismo pós-estruturalista, etc.), em suas investigações.

Supostamente neutros, os discursos científicos que tentavam naturalizar desigualdades entre mulheres e homens foram denunciados pelas investigações feministas, as quais passaram a utilizar do gênero para tal. Costa e Ribeiro (2011, p. 479) ressaltam que essa concepção de gênero "[...] contraria concepções como a de 'dom' e de 'essência', uma vez que nega o inatismo de características atribuídas a homens e mulheres e recorre aos processos sociais e históricos para explicar a constituição dos gêneros masculino e feminino", opondo-se, portanto, à concepção biologizante representada pela categoria anterior.

Com o tempo, o uso do gênero como categoria de análise das relações entre homens e mulheres foi aderido pelas mais diversas teorias feministas, revestindo-a com novos conceitos, para além da mera distinção funcionalista biológico/social, em que o sexo é uma base natural sobre a qual se constrói o gênero. Várias dessas teorias, principalmente as fundamentadas nas correntes pós-estruturalista e pósmodernista, tendo-se como exemplo Scott (1995), apontaram para a insuficiência do conceito funcionalista de gênero, que atribuía à biologia um status acrítico e a-histórico. A partir disso,

[...] um número crescente de feministas buscou compreender o sexo como uma categoria teórica totalmente determinada pela história e pela cultura, isto é, subsumida no interior da categoria gênero. Para essas feministas, são as formas sociais de compreensão da diferença e da semelhança entre homens e mulheres que determinam as maneiras como o corpo é apreendido, abandonando-se completamente a ideia de uma base natural fixa sobre a qual agiria a cultura (CARVALHO, 2011, p. 102).

No entanto, o gênero, enquanto um conceito que se soma ao sexo e não o substitui, referente à concepção representada pela presente categoria, ainda é, hoje, o conceito de gênero mais difundido entre os conceitos utilizados nas teorizações feministas, como ressaltam Carvalho e Rabay (2015), presente até mesmo no senso comum. Por isso, no título desta categoria, exprime-se próximo à concepção funcionalista por não haver, em momento algum, a interpelação de determinada teoria ou autor(a) da literatura que fornecesse aos(às) participantes da pesquisa o conhecimento sobre esse conceito, teoria e/ou autor(a) que, então, poderiam ter sido abordados em sua formação no curso de Pedagogia.

\section{GÊNERO COMO IDENTIDADE PESSOAL, ESCOLHIDA OU IDENTIFICADA, ORIENTADA ÀQUELAS HISTORICAMENTE AFIRMADAS OU PARA ALÉM DELAS}

A categoria denominada de Gênero como identidade pessoal, escolbida ou identificada, orientada àquelas bistoricamente afirmadas ou para além delas, foi constituída a partir dos indicadores extraídos das respostas de 31 sujeitos, concernente à $28,44 \%$ do total de respondentes. A concepção de gênero a qual representa não se refere nem ao sexo biológico e nem às construções sociais feitas sobre as diferenças sexuais, como as concepções representadas pelas duas categorias anteriores se referiram. O quadro 4 apresenta a categoria representativa dessa nova concepção de gênero.

Com base no Quadro 4, gênero, agora, é concebido como o processo de escolha ou de identificação a determinada identidade pessoal, seja ela respectiva aos gêneros feminino (mulher) ou masculino (homem), conforme foram historicamente afirmados, ou transcendendo-os, rompendo com esse binarismo identitário ao serem compostos por quaisquer atributos, sem distinções, como mais contemporaneamente esses "novos gêneros" têm sido referidos: gênero não-binário (non-binary), gênero fluido (gender fluid), etc. Em poucas palavras, refere-se a um dos aspectos que o gênero abarca: a identidade de gênero, sendo ela, em conceituação genérica, "[...] a maneira como alguém se sente e se apresenta para si e para os demais na condição de homem ou mulher ou, em alguns casos, de uma mescla de ambos" (Beto de JESUS et al., 2008, p. 35). 
Quadro 4 - Categoria representativa à concepção identitária de gênero das(os) participantes sobre o conceito de gênero

\begin{tabular}{|c|c|}
\hline Cat & idores \\
\hline \multirow{9}{*}{$\begin{array}{l}\text { 4. Gênero como identidade } \\
\text { pessoal, escolhida ou } \\
\text { identificada, orientada } \\
\text { àquelas historicamente } \\
\text { afirmadas ou para além } \\
\text { delas: o gênero é definido } \\
\text { voluntariamente, tratando-se } \\
\text { de uma opção; ou pelo próprio } \\
\text { entendimento de si, tratando- } \\
\text { se de uma identificação, e pode } \\
\text { se orientar às identidades } \\
\text { historicamente afirmadas, } \\
\text { mulher e homem, ou para além } \\
\text { delas, transcendendo as } \\
\text { fronteiras de gênero } \\
\text { (31; 28,44\%; n=109) }\end{array}$} & $2-$ Como as pessoas se identifican \\
\hline & $\begin{array}{l}\text { Sujeito } 23 \text { - Gênero para mim, é a orientação particular de um } \\
\text { indivíduo que não é classificado por apenas duas nomenclaturas } \\
\text { - feminino e masculino. }\end{array}$ \\
\hline & $\begin{array}{l}\text { Sujeito } 32 \text { - Eu compreendo por gênero masculino e feminino. } \\
\text { Gênero para mim é isso, se você se considera homem ou mulher. }\end{array}$ \\
\hline & $\begin{array}{l}\text { Sujeito } 39-\text { Gênero seria sua identidade sexual, seja nas } \\
\text { características femininas ou masculinas, seria a qual você mais se } \\
\text { encaixa, portanto é uma identidade escolhida. }\end{array}$ \\
\hline & $\begin{array}{l}\text { Sujeito } 45 \text { - Gênero está relacionado com as suas opções de } \\
\text { escolha. }\end{array}$ \\
\hline & $\begin{array}{l}\text { Sujeito } 97-\text { É quando uma pessoa se identifica como homem ou } \\
\text { mulher. }\end{array}$ \\
\hline & $\begin{array}{l}\text { Sujeito } 148 \text { - Gênero é a identificação do perfil da pessoa, } \\
\text { independente de qual corpo ela nasce, mas o que a atrai mais. }\end{array}$ \\
\hline & Sujeito 152 - Gênero é uma identificação. \\
\hline & Sujeito $158-\mathrm{O}$ que a pessoa escolhe ser. \\
\hline
\end{tabular}

Fonte: Dados da pesquisa

Legenda: $O$ quadro apresenta a quarta categoria identificada representativa às concepções das(os) participantes sobre o conceito de gênero, intitulada Gênero como identidade pessoal, escolbida on identificada, orientada àquelas historicamente afirmadas ou para além delas, junto aos indicadores extraídos das respostas que geraram essa categoria. A categoria foi formada a partir dos indicadores de 31 dos 109 sujeitos que responderam à pergunta de número 3 do questionário, o que concerniu a $28,44 \%$ dessa amostra.

Como já ressaltado, o gênero, enquanto identidade, constituiu-se na oposição femininomasculino em muitas culturas, sob influência do que, em cada época e lugar, convencionou-se sobre os papéis a serem desempenhados por todas(os) que compõem o meio social. Tomando-se como exemplo a cultura ocidental, a atribuição do gênero, de uma identidade previamente estabelecida, inicia-se com a identificação do sexo do bebê, às vezes ainda na barriga da mãe, com o preparo do enxoval rosa para meninas e azul para meninos, posteriormente determinando quais brinquedos, roupas e atividades que devem desempenhar, "[...] eles com carrinhos, dinossauros e soldados de brinquedo, preparando-se e assimilando-se à autonomia, à liderança e à agressividade; elas com miniaturas de utensílios domésticos, bonecas e pôneis, ajustando-se ao âmbito doméstico e resignado, à 'natureza', simulando a maternidade" (SILVA; BRABO, 2016, p. 133).

Teorias inatistas tentaram essencializar essas identidades, utilizando-se do determinismo biológico do discurso científico para tal. Ao contrário da concepção biológica de gênero trazida anteriormente, em que gênero é sinônimo de sexo, essas teorias tentam comprovar que um (sexo) determina o outro (gênero). Neste momento, vê-se a profusão e heterogeneidade teórica do campo dos Estudos de Gênero, que vai além da literatura de orientação feminista. Algumas dessas teorias provêm de áreas como da Neurociência, Biologia e Psicologia (Fernando Luiz CARDOSO, 2008; Joanalira Corpes MAGALHÃES; Paula Regina Costa RIBEIRO, 2009). 
Logo, a identificação a certa identidade, como presumido na argumentação dos sujeitos 2, 32, 97 e 152, é um processo inato, sem a participação do indivíduo, e boa parte dessas teorias ainda apontam que, se o gênero identificado não estiver de acordo com o feminino ou masculino conforme historicamente afirmados, trata-se de um desvio, pois são naturalmente inconcebíveis. Há abordagens menos conservadoras no trabalho com essas teorias (Joan SCOT'T, 1995; Lise ELIOT, 2013), inclusive assumidamente feministas, no entanto, discursos essencialistas advindos delas, como esse exposto, sobrevivem até hoje.

Teorias empiristas, contudo, vieram contrapô-las e, curiosamente, primeiro provindas das mesmas áreas biológicas citadas. Dessas, destacam-se aquelas que forneceram o conceito funcionalista de gênero, por médicos e psicólogos norte-americanos, como John Money e Robert Stoller. Esse conceito, como tratado anteriormente, em que o gênero se constrói sobre o sexo, foi então apropriado de forma acrítica pelas feministas na década de 1970. Porém, como também já tratado, com as teorizações feministas, principalmente as pós-estruturalistas, de que as identidades "não são dadas ou acabadas num determinado momento, [...] são instáveis e, portanto, passíveis de transformação" (LOURO, 1997, p. 27), colocando-se o sexo no páreo da cultura, outro conceito de gênero foi desenvolvido, embora não tenha aparecido entre as concepções de gênero da amostra de nossa pesquisa.

Esse conceito, hoje desenvolvido num corpo de teorizações denominado de Teoria Queer, trata o gênero não como um fenômeno que existe dentro dos indivíduos, pronto a ser descoberto e medido pelas(os) cientistas:

Pelo contrário, o gênero é um acordo que existe nas interações sociais: é precisamente aquilo que concordamos que seja. [...] tanto homens como mulheres, acabam por aceitar as distinções de gênero visíveis a nível estrutural e que se estabelecem ao nível interpessoal [...] ao assumirem para si próprios os traços de comportamento e papéis normativos para as pessoas do seu sexo, na sua cultura (NOGUEIRA, 2017, p. 103).

Mesmo que esse conceito aparente certa similaridade com as argumentações dos sujeitos 39, 45 e 152, sobre a assunção de identidade não ser inata, inclinamo-nos a inferir que isso ocorre por compreenderem as identidades feminina e masculina como as únicas possibilidades de existência, logo, para esses sujeitos, a não obediência às normas de gênero é consciente, uma simples escolha por "rebeldia", visto que não dispuseram de uma argumentação elaborada o suficiente para sustentar a compreensão desse conceito, provindo dos Estudos de Gênero pós-estruturalistas e queer, tão complexo e de difícil apreensão, até mesmo para acadêmicas(os).

\section{GÊNERO ASSOCIADO AO DESEJO SEXUAL}

A última das categorias identificadas, denominada de Gênero associado ao desejo sexual, foi constituída por meio dos indicadores das respostas de 15 sujeitos, equivalente a 13,76\% do total de respondentes. Nessa concepção, como também identificou Kelly da Silva (2015, p. 86) em outro contexto, relaciona-se indevidamente dois aspectos respectivos a dois temas, "[...] gênero e sexualidade", que, de fato, são relacionais, porém, na forma como são trazidos, "parece haver uma confusão entre esses conceitos", como mostra o quadro 5.

Com base no Quadro 5, verificou-se que gênero e sexualidade, sendo os aspectos da identidade de gênero e da orientação sexual mais especificamente, são tratados como sinonímias, como indicaram as argumentações dos sujeitos 68 e 127, ou são associados indevidamente de várias maneiras. Uma delas, de inversão conceitual, exemplificada pelos sujeitos 9, 68 e 129, ocorre ao se referirem aos gêneros, feminino e masculino, como orientações sexuais (aparecendo até sob a nomenclatura de opção, compreendendo o desejo sexual como um ato voluntário, como abordou a concepção anterior no que tange ao gênero) e as orientações sexuais, hetero e homossexualidade, como gêneros. Outra confusão, presente nas argumentações dos sujeitos 46 e 62, relaciona gênero exclusivamente com a sexualidade, sem qualquer apelo ao que, de fato, gênero pode representar (ex.: classificação, relações de gênero, identidade de gênero, etc.). 
Quadro 5 - Categoria representativa à concepção de gênero associada ao desejo sexual das(os) participantes sobre o conceito de gênero

\begin{tabular}{|c|c|}
\hline Categoria & Indicadores \\
\hline \multirow{6}{*}{$\begin{array}{l}\text { 5. Gênero associado ao } \\
\text { desejo sexual: gênero é } \\
\text { confundido com sexualidade, } \\
\text { não há distinção sequer } \\
\text { mínima entre identidade de } \\
\text { gênero e orientação sexual, } \\
\text { ambos são tratados como } \\
\text { sinonímias, a classificação do } \\
\text { desejo sexual é acrescentada } \\
\text { entre os gêneros afirmados } \\
\text { historicamente } \\
(\mathbf{1 5 ;} \mathbf{1 3 , 7 6 \% ; ~} \mathbf{n}=\mathbf{1 0 9 )}\end{array}$} & $\begin{array}{l}\text { Sujeito } 9 \text { - Compreendo como sendo a sexualidade, masculino, } \\
\text { feminino e suas opções sexuais. }\end{array}$ \\
\hline & Sujeito 46 - Gênero é a opção sexual escolhida por alguém. \\
\hline & Sujeito 62 - Algo ligado a sexualidade. \\
\hline & $\begin{array}{l}\text { Sujeito } 68 \text { - Para mim, o gênero sexual se refere no masculino e } \\
\text { feminino, mas há várias pessoas que têm outras opções de gênero, } \\
\text { como homossexuais, bissexuais. }\end{array}$ \\
\hline & $\begin{array}{l}\text { Sujeito } 127 \text { - É a opção sexual de cada pessoa (homem, mulher, } \\
\text { gay...). }\end{array}$ \\
\hline & $\begin{array}{l}\text { Sujeito } 129 \text { - É quando há mais de uma opinião, não existe } \\
\text { somente o feminino e masculino, existe o hétero, homossexual e } \\
\text { entre outros, mas que não são entendidos pela sociedade ainda. }\end{array}$ \\
\hline
\end{tabular}

Fonte: Dados da pesquisa

Legenda: $\mathrm{O}$ quadro apresenta a quinta categoria identificada representativa às concepções das(os) participantes sobre o conceito de gênero, intitulada Gênero associado ao desejo sexual, junto aos indicadores extraídos das respostas que geraram essa categoria. A categoria foi formada a partir dos indicadores de 15 dos 109 sujeitos que responderam à pergunta de número 3 do questionário, o que concerniu a $13,76 \%$ dessa amostra.

Segundo Beatriz Accioly Lins, Bernardo Fonseca Machado e Michele Escoura (2016, p. 6970), impera-se culturalmente o que se chama de matriz de gênero, isto é, a associação de corpo, identidade de gênero, desejos e práticas sexuais, esperando-se a seguinte coerência entre esses aspectos: "pensamos que uma pessoa que nasceu com um pênis (corpo), por exemplo, automaticamente irá se comportar como um homem (identidade de gênero), sempre se sentirá atraído afetiva e sexualmente por mulheres (desejo) e só com elas manterá relações sexuais (práticas sexuais)". O público da diversidade sexual e de gênero, contudo, atesta que muitas outras combinações são possíveis entre os aspectos que compõem essa matriz.

Assim, gênero e sexualidade relacionam-se como duas dimensões da identidade humana, que se entrecruzam como marcadores da diferença, mas que ainda assim distinguem-se nitidamente. Tomando-se o público da diversidade como exemplo, "travestis e transexuais são pessoas cuja identidade de gênero difere daquela esperada para seu corpo. Isso não quer dizer que sejam homossexuais, até porque identidade de gênero e orientação sexual não são a mesma coisa" (LINS; MACHADO; ESCOURA, 2016, p. 76). Esse público, que transgride a referida matriz, cuja consolidação foi responsável pela confusão que resultou na presente categoria representativa, é focalizado pela Teoria Queer, tendo sua transgressão como objeto de estudo.

\section{CONSIDERAÇÕES FINAIS}

Neste artigo, procuramos apresentar resultados parciais de uma pesquisa concluída, obtidos com a aplicação de um questionário. Com uma revisão profícua do conceito de gênero a partir das concepções de uma amostra de graduandas(os) em Pedagogia no contexto da formação superior pública paulista, as concepções de gênero identificadas, divididas em cinco categorias representativas dessas concepções, estiveram bem distribuídas entres as(os) participantes, sem prevalência significativa entre 
elas, ainda que as primeira e última concepções não passaram de $20 \%$ enquanto as três restantes excederam pouco mais dos 30\%. É relevante ressaltar que metade das(os) participantes estava no primeiro ano do curso e a outra metade no último ano, sendo que a formação da cinco concepções contou com respostas de sujeitos de ambos os anos, ingressantes e concluintes.

Com base na literatura e documentos oficiais consultados e citados anteriormente (o PNEDH e as DNEDH), na pesquisa constatamos que a formação das(os) graduandas(os) está aquém do que é esperado, como também constataram Ribeiro (2011) e Dinis e Cavalcanti (2008) dentro da proposta de suas pesquisas. Considerando que as DNEDH normatizam e regulamentam o trabalho nas licenciaturas, bem como o PNEDH que lhes servem de parâmetro, espera-se que, na EDH, promova-se "uma formação ética, crítica e política":

A primeira se refere à formação de atitudes orientadas por valores humanizadores, como a dignidade da pessoa [...]. A formação crítica diz respeito ao exercício de juízos reflexivos [...] promovendo práticas institucionais coerentes com os Direitos Humanos. A formação política deve estar pautada numa perspectiva emancipatória e transformadora dos sujeitos de direitos. Sob esta perspectiva promover-se-á o empoderamento de grupos e indivíduos, situados à margem de processos decisórios e de construção de direitos (BRASIL, 2012, p. 8-9).

Mas para que essa formação seja proporcionada, docentes, que participarão privilegiadamente nessa formação, necessitam dispor de concepções mais elaboradas e emancipatórias sobre os temas, visto que, e como a pesquisa pressupôs dialogando com seu referencial hermenêutico, são as concepções dessas(es) profissionais que pautarão sua atuação na escola, em contato direto e cotidiano com a diversidade. Logo, quanto mais sua concepção sobre gênero for constituída por conhecimentos científicos com um projeto emancipatório, tal como é o feminista, mais chances sua atuação oriunda dessa concepção, a ação que desempenhará na escola, tem em ser satisfatória no tratamento da diversidade sexual e de gênero e no desenvolvimento de um trabalho que aborde a temática.

No entanto, no que tange ao exposto neste artigo, observamos que as concepções de gênero desses sujeitos não lhe amparam em sua atuação futura junto à diversidade de gênero na escola ou no desenvolvimento de um trabalho que aborde a temática. Inferimos que as(os) participantes não detêm uma formação em gênero fundada no conhecimento científico proveniente das produções da literatura de gênero feminista, com exceção das(os) que compreendem gênero nas perspectivas identitária e funcionalista, mas que se mostram em noções frágeis e sem a evocação de determinada teoria ou autor(a) da literatura.

A literatura de gênero feminista consultada correspondeu, sobretudo, às(os) autoras(es) apresentadas(os) na discussão da concepção funcionalista de gênero, bem como outras(os) autoras(es) também citadas(os) ao longo do artigo, as(os) quais "em suas múltiplas perspectivas teóricas, mas que têm em comum o caráter político de igualdade, podem se constituir numa produtiva referência e serem adotados como bússola nas discussões acerca dos gêneros" (FURLANI, 2016a, p. 40). Como se viu, no entanto, as concepções evidenciadas requereram fundamentação em outras literaturas que não feministas no estudo de gênero, mostrando que a maior parte dos sujeitos dispõem de concepções pouco potenciais para a contemplação do referido projeto de educação amparado legalmente. Concepções mais conservadoras, ou pelo menos pouco potenciais, sobre gênero também foram constatadas por Costa e Ribeiro (2011) e Dinis e Cavalcanti (2008) em suas respectivas amostras de graduandas(os) em Pedagogia.

Verificamos que nossa pesquisa foi a primeira realizada no curso de Pedagogia em questão que procurou investigar a formação nele oferecida sobre as temáticas de gênero e sexualidades, o que é muito preocupante, uma vez que o curso está em vigência há mais de 60 anos. Por isso, o diagnóstico aqui relatado que viabilizamos pioneiramente sobre a formação do alunado desse curso em específico mostrou-se não só pertinente como também necessário para investigações futuras, sobretudo interventivas, visto que para qualquer intervenção em determinada realidade deve-se partir de algo palpável, de um diagnóstico que se tem conhecimento ou que se deve procurar ter da realidade a ser transformada. 
Assim, um programa de pesquisa, iniciado com a pesquisa concluída aqui tratada, segue continuidade com uma pesquisa seguinte ${ }^{9}$, atualmente em andamento, na qual esperamos obter maiores contribuições sobre o estado da formação da Educação Superior e pistas de como melhorá-la, analisandose, agora, a formação da(o) psicóloga(a) junto à formação da(o) pedagoga(o) no que se refere às temáticas de gênero e sexualidades e também à ética. Vale ressaltar que, nessa pesquisa em andamento, também se considera a variável curricular das graduações participantes, bem como outros documentos gerais, como as Diretrizes Curriculares Nacionais para o curso de graduação em Pedagogia (BRASIL, 2006), que não foi objeto de análise da pesquisa anterior (que se ateve somente aos documentos oficiais da EDH).

A Universidade tem parte da responsabilidade na produção das concepções de gênero de suas(seus) estudantes. Cabe, agora, analisar em que medida ela mesma não produz e reproduz essas concepções e questionar se seu currículo e Projeto Político-Pedagógico viabiliza o que os documentos oficiais pertinentes orientam e estipulam.

\section{REFERÊNCIAS}

BARDIN, Lawrence. Análise de conteúdo. Trad. Luís Antero Reto. São Paulo: Edições 70, 2016.

BEAUVOIR, Simone de. O segundo sexo: a experiência vivida. Trad. Sérgio Milliet. 3. ed. Rio de Janeiro: Nova Fronteira, 2016. v. 2.

BLATT, Moshe M.; KOHLBERG, Lawrence. The effects of classroom moral discussion upon children's level of moral judgment. Journal of Moral Education, v.4, n.2, p.129-161, 1975.

BLEICHER, Josef. Hermenêutica contemporânea. Trad. Maria Georgina Segurado. Lisboa: Edições 70, 2002.

BRABO, Tânia Suely Antonelli Marcelino. Cidadania da mulher professora. São Paulo: Ícone, 2005. BRABO, T. S. A. M. Movimentos sociais e educação: feminismo e equidade de gênero. In: DAL RI, N. M.; BRABO, T. S. A. M. (Org.). Políticas educacionais, gestão democrática e movimentos sociais. Marília: Oficina Universitária/Cultura Acadêmica, 2015. p. 109-128.

BRASIL. Ministério da educação, conselho nacional de educação. Resolução no 1 , de 30 de maio de 2012. Estabelece diretrizes nacionais para a educação em direitos humanos. CNE/CP: Diário Oficial da União, Brasília, DF, 2012.

BRASIL. Ministério da Educação, Conselho Nacional de Educação. Resolução CNE/n. ${ }^{\circ}$, de 15 de maio de 2006. Institui Diretrizes Curriculares Nacionais para o curso de graduação em Pedagogia, licenciatura. CNE/CP: Diário Oficial da União, Brasília, DF, 2006.

9 Essa pesquisa tem como título Competência moral, gênero e sexualidades, e religiosidade na formação inicial pública paulista em Pedagogia e Psicologia e contou com o financiamento do CNPq, pelo processo de n. ${ }^{\circ}$ 131735/2020-9 no período de 01/03/2020 a 31/10/2020, e atualmente conta com o financiamento da FAPESP, pelo processo de n. ${ }^{\circ}$ 2020/05099-9 e com previsão de vigência de 01/11/2020 a 31/01/2022, sob orientação da Prof. ${ }^{a}$ Dr. ${ }^{a}$ Patrícia Unger Raphael Bataglia e co-orientação da Prof. ${ }^{a}$ Dr. ${ }^{a}$ Tânia Suely Antonelli Marcelino Brabo. Disponível em: https://bv.fapesp.br/pt/bolsas/196030/competencia-moralgenero-e-sexualidades-e-religiosidade-na-formacao-inicial-publica-paulista-em-peda/ 
BRASIL. Comitê Nacional de Educação em Direitos Humanos. Plano nacional de educação em direitos humanos. Brasília, DF: Secretaria de Direitos Humanos; Ministério da Educação; UNESCO, 2007.

BRASIL. Comitê Nacional de Educação em Direitos Humanos. Plano nacional de educação em direitos humanos. 2. ed. Brasília, DF: Secretaria de Direitos Humanos; Ministério da Educação; UNESCO, 2013.

BUTLER, Judith. Gender trouble: feminism and the subversion of identity. 2nd. ed. New York: Routledge, 2007.

CARDOSO, Fernando Luiz. Etiologia da orientação sexual e suas implicações para a ciência do movimento humano/ etiologia da orientação sexual. Motrivivência, v. 20, n. 30, p. 197-216, jun., 2008.

CAMPOS-TOSCANO, Ana Lúcia Furquim. O percurso dos gêneros do discurso publicitário: uma análise das propagandas da Coca-Cola. São Paulo: Editora UNESP; São Paulo: Cultura Acadêmica, 2009.

CARVALHO, Maria Eulina Pessoa de; RABAY, Glória. Usos e incompreensões do conceito de gênero no discurso educacional no Brasil. Estudos Feministas, Florianópolis, v. 23, n. 1, 119-136, jan./abr., 2015.

CARVALHO, Marília Pinto de. O conceito de gênero: uma leitura com base nos trabalhos do GT Sociologia da Educação da ANPEd (1999-2009). Revista Brasileira de Educação, Rio de Janeiro, v. 16, n. 46, p. 99-117, jan./abr., 2011.

CASTRO, Roney Polato de. Educação, relações de gênero e sexualidades: experiências de estudantes de pedagogia. Revista da FAEEBA - Educação e Contemporaneidade, Salvador, v. 25, n. 45, p. 203-214, jan./abr. 2016.

COSTA, Ana Paula; RIBEIRO, Paulo Rennes Marçal. Ser professora, ser mulher: um estudo sobre concepções de gênero e sexualidade para um grupo de alunas de pedagogia. Estudos Feministas, Florianópolis, v. 19, n. 2, p. 475-489, maio/ago., 2011.

CUNHA, Antonio Geraldo da. Dicionário etimológico nova fronteira da língua portuguesa. Rio de Janeiro: Nova Fronteira, 1982.

DINIS, Nilson Fernandes; CAVALCANTI, Roberta Ferreira. Discursos sobre homossexualidade e gênero na formação em pedagogia. Pro-Posições, v. 19, v. 56, n. 2, maio/ago., 2008.

ELIOT, Lise. Cérebro azul ou rosa: impacto das diferenças de gênero na educação. Trad. Maria Adriana Veríssimo Veronese. Porto Alegre: Penso, 2013.

GIL, Antonio Carlos. Métodos e técnicas de pesquisa social. 6. ed. São Paulo: Atlas, 2008. 
HARDING, Sandra. The science question feminism. Ithaca and London: Cornell University Press, 1986.

JESUS, Beto de et al. Diversidade sexual na escola: uma metodologia de trabalho com adolescentes e jovens. Ed. Especial, revista e ampliada. São Paulo: ECOS, 2008.

FURLANI, Jimena. Educação sexual na sala de aula: relações de gênero, orientação sexual e igualdade étnico-racial numa proposta de respeito às diferenças. Belo Horizonte: Autêntica, 2016a.

FURLANI, Jimena. "Ideologia de Gênero"? Explicando as confusões teóricas presentes na cartilha". Versão Revisada 2016b. Florianópolis: FAED, UDESC. Laboratório de Estudos de Gênero e Família, 2016. Disponível em: <https://www.facebook.com/jimena.furlani>. Acesso em: 15 jan. 2021.

KOHLBERG, Lawrence. Psicologia del desarrollo moral. Bilbao, Espanha: Editorial Desclée de Brower, 1992.

LEMOS DE SOUZA, Leonardo. Leituras periféricas: gêneros e sexualidades como expressões e saberes na educação escolar. In: Anais do IX Seminário internacional redes: educação e democracia - aprenderensinar para um mundo plural e igualitário. Rio de Janeiro: UERJ, 2017. p. $1-15$.

LINS, Beatriz Accioly; MACHADO, Bernardo Fonseca. ESCOURA, Michele. Diferentes, não desiguais: a questão de gênero na escola. São Paulo: Editora Reviravolta, 2016.

LOURO, Guacira Lopes. Gênero, sexualidade e educação: uma perspectiva pós-estruturalista. 6. ed. Petrópolis: Vozes, 1997.

LUCCHESI, Dante. A concordância de gênero. In: LUCCHESI, Dante; BAXTER, Alan; RIBEIRO, Ilza (Org.). O português afro-brasileiro. Salvador: EDUFBA, 2009. p. 295-318.

LÜDKE, Menga; ANDRÉ, Marli E. D. A. Pesquisa em educação: abordagens qualitativas. São Paulo: EPU, 1986.

MAGALHÃES, Joanalira Corpes; RIBEIRO, Paula Regina Costa. As neurociências ensinando modos de ser homem e mulher em revistas de divulgação científica. Revista Electrónica de Enseñanza de las Ciencias, v. 8, n. 2, 2009.

MARCONI, Marina de Andrade; LAKATOS, Eva Maria. Fundamentos da metodologia científica. 5. ed. São Paulo: Atlas, 2003.

MATOS, Daniel Abud Seabra; JARDILINO, José Rubens Lima. Os conceitos de concepção, percepção, representação e crença no campo educacional: similaridades, diferenças e implicações para a pesquisa. Educação \& Formação, Fortaleza, v. 1, n. 3, p. 20-31, set./dez., 2016.

NOGUEIRA, Conceição. Interseccionalidade e psicologia feminista. Salvador: Devires, 2017. 
PLEBE, Armando. Breve história da retórica antiga. São Paulo: E.P.U., 1978.

REST, R. James; NARVAEZ, Darcia; BEBEAU, Muriel J; THOMA, Stephen J. Postconventional moral thinking: a neo-kohlbergian approach. Mahwah: Lawrence Erlbaum Associates, 1999. ROHDEN, Fabíola. A construção da diferença sexual na medicina. Cad. Saúde Pública, Rio de Janeiro, v. 19, n. 2, p. 201-212, 2003.

SCOTT, Joan. W. Gênero: uma categoria útil de análise histórica. Trad. Guacira Lopes Louro.

Educação \& Realidade, Porto Alegre, v. 20, n. 2, p. 71-99, jul./dez., 1995.

SILVA, Kelly da. Currículo e gênero: a sexualidade na formação docente. Curitiba: Appris, 2015.

SILVA, Matheus Estevão Ferreira da. Dilemas morais de graduandos(as) em Pedagogia sobre a diversidade sexual e de gênero na escola. In: ABUD, Cristiane de Castro Ramos (Org.). Gênero e diversidade no contexto escolar. Rio de Janeiro: Eulim, 2019. p. 183-200.

SILVA, Matheus Estevão Ferreira da. Relevância dos temas gênero e sexualidades para a educação escolar de crianças: o que pensam os(as) pedagogo(as)?. Revista latinoamericana de educación inclusiva, v. 14, n. 1, p. 69-83, 2020.

SILVA, Matheus Estevão Ferreira da; BRABO, Tânia Suely Antonelli Marcelino. A introdução dos papéis de gênero na infância: brinquedo de menina e/ou de menino?. Revista Trama

Interdisciplinar, São Paulo, v. 7, n. 3, p. 127-140, set./dez., 2016.

SILVA, Matheus Estevão Ferreira da; BRABO, Tânia Suely Antonelli Marcelino; MORAIS, Alessandra de. Educação em direitos humanos e desenvolvimento moral na formação docente: a influência da religiosidade em tempos de "ideologia de gênero". Revista on line de Política e Gestão

Educacional, Araraquara, v. 21, n. esp. 2, p. 1260-1282, nov., 2017.

SILVA E SOUZA, Maewa Martina Gomes da. Concepções de crianças não deficientes acerca das deficiências: estudo realizado com crianças de 4 a 6 anos de idade. 2010. 45 f. Trabalho de Conclusão de Curso (Graduação em Pedagogia) - Faculdade de Filosofia e Ciências (FFC), Universidade Estadual Paulista "Júlio de Mesquita Filho" (UNESP), Marília, 2010.

STATISTICAL PACKAGE FOR THE SOCIAL SCIENCES. SPSS@ for Windows 10. New York: IBM Corporation, 2017.

Submetido: $17 / 02 / 2020$

Aprovado: 18/01/2021 